\title{
UTILIZAÇÃO DE DIFERENTES DILUENTES NA CRIOPRESERVAÇÃO DE ESPERMATOZOIDES DE GARANHÕES MANGALARGA MARCHADOR
}

\section{USE OF DIFFERENT EXTENDERS TO CRYOPRESERVATION OF MANGALARGA MARCHADOR SPERM}

\author{
Jessica Neri Nascimento ${ }^{1}$ \\ Hélio Blume ${ }^{2}$ \\ Francisco José Gonçalves Oliveira ${ }^{3}$ \\ Rodrigo Arruda Oliveira ${ }^{*}$
}

${ }^{1}$ Central de Reprodução Equina JN, Unaí, MG, Brasil.

${ }^{2}$ Faculdades Integradas UPIS, Departamento de Medicina Veterinária, Brasília, DF, Brasil.

${ }^{3}$ Gonçalves de Oliveira Serviços Veterinários Ltda., Brasília, DF, Brasil

${ }^{4}$ Universidade de Brasília, Faculdade de Agronomia e Medicina Veterinária, Brasília, DF, Brasil

*Autor para correspondência - rodrigoarruda@unb.br

\section{Resumo}

As biotécnicas aplicadas à reprodução animal como inseminação artificial, transferência e produção in vitro de embriões, indução e sincronização de cio e congelamento de gametas vêm sendo cada vez mais utilizadas na prática veterinária. No entanto, algumas biotécnicas ainda não alcançaram o seu total aperfeiçoamento técnico na reprodução equina, como a criopreservação de sêmen. Objetivou-se avaliar as características pós-descongelamento (motilidade total, vigor e integridade de membrana plasmática e acrosomal) dos espermatozoides de garanhões da raça Mangalarga Marchador ( $n=5)$, empregando-se três diluentes de criopreservação. Após a colheita, o sêmen foi diluído na proporção de 1:1 em meio à base de leite em pó desnatado e centrifugado a $600 \mathrm{G}$ por 10 minutos. Após a centrifugação, o sobrenadante foi desprezado e o pellet obtido dividido e ressuspendido com Botucrio, FR5 ou FR6. As amostras foram envasadas em palhetas de 0,5 mL sendo a concentração ajustada para $200 \times 10^{6}$ espermatozoides $/ \mathrm{mL}$. As palhetas foram distribuídas em uma plataforma-suporte e estabilizadas a $5{ }^{\circ} \mathrm{C} / 60 \mathrm{~min}$., em refrigerador comercial. Para o congelamento, as palhetas, posicionadas horizontalmente, foram expostas por 15 minutos ao vapor de nitrogênio líquido, em uma caixa de isopor, a $6 \mathrm{~cm}$ acima do nível de nitrogênio líquido. Logo em seguida, as palhetas foram imersas no nitrogênio líquido, acondicionadas em raques e estocadas em botijão criogênico a $-196{ }^{\circ} \mathrm{C}$, para posterior avaliação. Não houve diferença para as variáveis motilidade, vigor e integridade das membranas plasmática e acrossomais quando se utilizaram diluentes que contêm a associação de amidas e glicerol (Botucrio e FR6; P>0,05). As variáveis seminais no diluente contendo apenas glicerol foram inferiores em todas as avaliações $(\mathrm{P}<0,05)$. A utilização de crioprotetores como a metilformamida, em associação com concentrações de 1 ou $2 \%$ 
de glicerol é uma alternativa para a criopreservação do sêmen de garanhões da raça Mangalarga Marchador.

Palavras-chave: amidas; crioprotetor; equino; glicerol; sêmen congelado.

\begin{abstract}
The techniques applied to animal reproduction such as artificial insemination, transfer and in vitro production of embryos, heat synchronization and induction, and gametes cryopreservation have been more utilized in veterinary practice each day. Nevertheless, some techniques have not achieved their full technical capacity within the equine reproduction field, such as semen cryopreservation. The aim of this study was to evaluate the characteristics of post-thawing semen (total motility, strength, plasmatic and acrosomal membrane integrity) of Mangalarga Marchador breed stallions, using three different extenders (Botucrio, FR5 and FR6). Ejaculates from five stallions were collected and the gel-free semen was diluted in a 1:1 dilution in skim milk extender, and centrifuged at $600 \mathrm{~g}$ for 10 minutes. After the centrifugation the supernatant was removed and sperm pellet was divided and re-suspended using three different extenders to a concentration of 200 x $10^{6}$ cells $/ \mathrm{mL}$. The samples were packed into $0.5 \mathrm{~mL}$ straws, placed in a stainless steel support and kept inside the refrigerator $\left(5^{\circ} \mathrm{C}\right)$ for one hour. Subsequently, these straws were kept at a height of 6 $\mathrm{cm}$ from liquid nitrogen for 15 minutes in an isotherm box and, after that, plunged into liquid nitrogen $\left(-196{ }^{\circ} \mathrm{C}\right)$ and stored in a liquid nitrogen holding tank. There were no differences in the parameters evaluated when extenders using mixed amides and glycerol (Botucrio and FR6) were used $(\mathrm{P}>0.05)$. All parameters evaluated were lower for the extender containing only glycerol $(\mathrm{P}<0.05)$. The use of cryoprotectants (methylformamide and dimethylformamide) in association with glycerol concentrations around 1 to $2 \%$ is an alternative for semen cryopreservation of Mangalarga Marchador breed stallions.
\end{abstract}

Keywords: amides; cryoprotectant; equine; frozen semen; glycerol.

Recebido em: 13 novembro 2012

Aceito em: 22 abril 2015

\title{
Introdução
}

As biotécnicas aplicadas à reprodução animal como inseminação artificial, transferência e produção in vitro de embriões, indução e sincronização de cio e congelamento de gametas vêm sendo cada vez mais utilizadas na prática veterinária. No entanto, algumas biotécnicas ainda não alcançaram o seu total aperfeiçoamento técnico dentro da reprodução equina, como a criopreservação de sêmen ${ }^{(1)}$. Os grandes entraves encontrados referem-se ao menor potencial fecundante do sêmen após o descongelamento, maiores custos com materiais, inseminação no momento mais próximo da ovulação, técnicas utilizadas durante inseminação artificial e as variações entre garanhões da mesma raça e de raças diferentes ${ }^{(2)}$.

O desenvolvimento de técnicas adequadas para preservação e armazenamento de sêmen possibilita o melhor aproveitamento de animais com alto valor zootécnico, evita gastos e riscos com transporte de animais e permite a conservação de material genético por tempo indeterminado ${ }^{(2)}$.

Dentre as raças nacionais, o Mangalarga Marchador tem seu sêmen considerado como de baixa 
congelabilidade; desta forma, estudos são necessários para que se estabeleçam protocolos mais eficazes para a criopreservação do sêmen deste genótipo ${ }^{(3)}$. A concentração e o tipo do crioprotetor, além dos demais componentes do diluente de congelamento, interferem diretamente na viabilidade da célula após o descongelamento. Com base no exposto, o presente estudo teve por objetivo comparar três diluentes na criopreservação do sêmen de garanhões da raça Mangalarga Marchador.

\section{Material e Métodos}

Foram utilizados cinco garanhões adultos da raça Mangalarga Marchador. Foi realizado o esgotamento prévio das reservas espermáticas extragonadais, com colheitas em dias alternados, por sete dias, e os animais foram submetidos à avaliação andrológica ${ }^{(4)}$. Em seguida, foram realizadas três colheitas, em dias alternados, de cada garanhão, totalizando 15 ejaculados criopreservados.

Imediatamente após a colheita do sêmen foram avaliados o volume, aspecto e odor. À avaliação microscópica, estimaram-se os valores de motilidade total e vigor espermático. Foram utilizados para o congelamento apenas os ejaculados com motilidade total $\geq 60 \%$ e vigor $\geq 4$.

O sêmen foi diluído na proporção de 1:1 em meio à base de leite em pó desnatado (Botu-sêmen ${ }^{\circledR}$, Botupharma, Brasil) e centrifugado a $600 \mathrm{G}$ por 10 minutos. Após a centrifugação, o sobrenadante foi desprezado e o pellet ressuspendido em três diluentes de criopreservação, tendo as seguintes composições de crioprotetores: $1 \%$ de glicerol e $4 \%$ de metilformamida (Botucrio ${ }^{\circledR}$, Botupharma, Brasil); $5 \%$ de glicerol (FR5 ${ }^{\circledR}$, Nutricell, Brasil); e $2 \%$ de glicerol e $3 \%$ de dimetilformamida (FR6 ${ }^{\circledR}$, Nutricell, Brasil).

As amostras foram envasadas em palhetas de $0,5 \mathrm{~mL}$, com concentração ajustada para $200 \times 10^{6}$ espermatozoides $/ \mathrm{mL}$, e lacradas com massa de modelar atóxica e colorida. As palhetas foram distribuídas em uma plataforma-suporte e estabilizadas a $5{ }^{\circ} \mathrm{C} / 60 \mathrm{~min}$., em refrigerador comercial. Para o congelamento em plataforma-suporte, as palhetas foram posicionadas horizontalmente a 6 $\mathrm{cm}$ acima do nível de nitrogênio líquido e expostas ao vapor de nitrogênio líquido por 15 minutos. Logo em seguida, as palhetas foram imersas no nitrogênio líquido, acondicionadas em raques e estocadas em botijão criogênico a $-196^{\circ} \mathrm{C}$, para posterior avaliação.

Após ficarem armazenadas por 90 dias, as amostras foram descongeladas à $37^{\circ} \mathrm{C}$ por 30 segundos, para avaliação da motilidade total, vigor espermático e integridade das membranas plasmática e acrossomais. As avaliações da motilidade total e vigor espermáticos foram realizadas por microscopia óptica, em aumento de 200x, e os valores expressos em porcentagem de 0 a $100 \%$ e em conformidade com escala de 0 a 5 , respectivamente ${ }^{(4)}$.

Para avaliação da integridade de membrana plasmática foram utilizadas as sondas fluorescentes iodeto de propídeo (IP) e diacetato de 6-carboxifluoresceína (CFDA), conforme técnica descrita por Harrison e Vickers ${ }^{(5)}$. Foram avaliadas 200 células em microscopia de epifluorescência no aumento de 1000x. Para análise da integridade da membrana acrossomal foi utilizada a sonda fluorescente isotiocianato de fluoresceína conjugada com a aglutinina do amendoim (Arachis hypogaea) (FITCPNA) e iodeto de propídeo (IP), como descrito por Klinc e Rath ${ }^{(6)}$. Foram avaliadas 200 células em microscopia de epifluorescência alternada com o contraste de fase, no aumento de 1000x.

Os dados foram submetidos à análise de variância por meio do software Statistical Analysis System (SAS) pelo procedimento GLM, e para o teste de médias utilizou-se Tukey em nível de 5\% de significância. 


\section{Resultados}

A motilidade total e vigor espermáticos médios após a colheita do sêmen foram $75,83 \pm 18,67 \%$ e $3,2 \pm 0,6$, respectivamente. Os valores médios de motilidade total, vigor e integridade das membranas plasmática e acrossomal, referentes aos três diluentes de criopreservação, estão apresentados na Tabela 1.

Tabela 1: Valores médios $( \pm \mathrm{DP})$ de motilidade total, vigor, integridade das membranas plasmática (INTMP) e acrossomal (INTAC) do sêmen de garanhões da raça Mangalarga Marchador ( $\mathrm{n}=5$ ) criopreservado em diluentes contendo diferentes tipos e concentrações de crioprotetores

\begin{tabular}{ccccc}
\hline Diluentes & $\begin{array}{c}\text { Motilidade total } \\
\mathbf{( \% )}\end{array}$ & $\begin{array}{c}\text { Vigor } \\
(\mathbf{0}-\mathbf{5})\end{array}$ & INTMP (\%) & INTAC (\%) \\
\hline Botucrio & $51,11^{\mathrm{a}} \pm 14,88$ & $2,7^{\mathrm{a}} \pm 0,66$ & $56,88^{\mathrm{a}} \pm 3,56$ & $55,38^{\mathrm{a}} \pm 4,79$ \\
FR5 & $19,44^{\mathrm{b}} \pm 11,22$ & $1,4^{\mathrm{b}} \pm 0,72$ & $48,27^{\mathrm{b}} \pm 4,55$ & $46,77^{\mathrm{b}} \pm 4,25$ \\
FR6 & $40,55^{\mathrm{a}} \pm 15,10$ & $2,3^{\mathrm{a}} \pm 0,83$ & $55,44^{\mathrm{a}} \pm 2,50$ & $53,01^{\mathrm{a}} \pm 4,93$ \\
\hline
\end{tabular}

Letras diferentes na coluna indicam diferença significativa entre médias pelo teste de Tukey $(\mathrm{P}<0,05)$

Com base nos resultados obtidos, constatou-se que, para os diluentes que continham a associação entre amidas e o glicerol (Botucrio e FR6), não houve diferença para as variáveis motilidade, vigor e integridade das membranas plasmática e acrossomal $(\mathrm{P}>0,05)$. No entanto, o diluente contendo apenas o glicerol (FR5) como crioprotetor resultou em valores inferiores para todas as variáveis analisadas $(\mathrm{P}<0,05)$.

\section{Discussão}

Devido à variação na resposta do sêmen de diferentes garanhões ao congelamento, deve-se estar atento à utilização de sêmen criopreservado que atenda às características desejáveis de qualidade para o uso na inseminação $\operatorname{artificial~}^{(4)}$.

A superioridade dos diluentes contendo metilformamida e dimetilformamida e o glicerol, em concentrações menores (Botucrio e FR6), observada no presente experimento, deve-se ao menor peso molecular e viscosidade das amidas, em relação ao glicerol, o que faz com que o crioprotetor penetre de forma mais rápida através da membrana plasmática, protegendo-a de forma mais eficaz e causando menores danos celulares ${ }^{(7)}$. Ao avaliarem diferentes crioprotetores, para a criopreservação do ejaculado de 20 garanhões de diferentes raças, Medeiros et al. ${ }^{(8)}$ observaram $27 \%$ de células móveis pós-descongelamento para o diluente contendo glicerol e $52 \%$ naquele com dimetilformamida $(\mathrm{P}<0,05)$. Para a criopreservação de espermatozoides de 55 garanhões de diferentes raças com diluentes contendo $5 \%$ de glicerol ou $5 \%$ de dimetilformamida como crioprotetores, Alvarenga et al. ${ }^{(9)}$ verificaram motilidade progressiva superior com a 
dimetilformamida. Os autores relataram que a frequência de garanhões com motilidade pósdescongelamento superior a $40 \%$ foi, para o sêmen congelado com o glicerol, de $38 \%$ (21/55) e para a dimetilformamida, de $80 \%$ (40/55).

Terraciano et al. ${ }^{(10)}$ demonstraram que diluentes à base de amidas são mais eficazes na proteção aos espermatozoides, resultando em motilidade progressiva pós-descongelamento superior quando comparado aos que contém apenas glicerol (FR5). Candeias et al. ${ }^{(11)}$, ao avaliarem três meios de criopreservação, dois deles com $4 \%$ de glicerol e outro com $1 \%$ de glicerol e $4 \%$ de metilformamida, obtiveram efeitos superiores de motilidade total para este último. $\mathrm{O}$ mesmo resultado foi encontrado com os meios utilizados no presente experimento, em que as variáveis analisadas foram superiores para os que contêm 1 ou $2 \%$ de glicerol e a metilformamida. Esses resultados também estão de acordo com Gomes et al. ${ }^{(3)}$ e Medeiros et al. ${ }^{(8)}$, que trabalharam com reprodutores Mangalarga Marchador, e Oliveira et al. ${ }^{(12)}$, com garanhões da raça Crioula.

A toxicidade do glicerol já foi relatada por alguns autores ${ }^{(13,14)}$, demonstrando efeito contraceptivo na égua, por reduzir a fertilidade do sêmen equino quando incluído nos diluentes usados para sêmen fresco, refrigerado e congelado. Alvarenga et al. ${ }^{(15)}$ observaram que o glicerol em concentrações próximas a 5\% foi o crioprotetor que induziu ao maior estresse osmótico na célula espermática, levando à redução dos valores das variáveis motilidade, viabilidade e integridade de membrana, fato também observado para o sêmen criopreservado dos garanhões da raça Mangalarga Marchador com o FR5. Pace e Sullivan ${ }^{(16)}$ verificaram que o glicerol em concentrações superiores a 3\%, ou quando usado de forma isolada em concentrações superiores a 5\%, exerce efeito tóxico sobre o espermatozoide equino, fato esse evidenciado para garanhões de raças consideradas de baixa congelabilidade, como o Mangalarga Marchador e outras raças nacionais ${ }^{(3,8,11,12)}$.

Os resultados superiores de integridade das membranas plasmática e acrossomais encontrados neste experimento com os diluentes contendo metilformamida corroboram os resultados de Terraciano et al. $^{(10)}$ e Medeiros ${ }^{(17)}$; contudo, Alvarenga et al. ${ }^{(9)}$, Candeias et al. ${ }^{(11)}$ e Ferreira ${ }^{(18)}$ não observaram diferenças na preservação da integridade de membrana quando compararam protocolos de criopreservação com glicerol e amidas.

Neste experimento, quando se utilizou apenas o glicerol como crioprotetor (FR5), o resultado de motilidade total pós-descongelamento foi $30 \%$, enquanto para concentrações de 1 ou $2 \%$ de glicerol, em combinação com a metilformamida e dimetilformamida (Botucrio e FR6), a motilidade foi superior a 30\%, dados semelhantes aos encontrados por Candeias et al. ${ }^{(11)}$ e Oliveira et al. ${ }^{(12)}$. Gomes et al. ${ }^{(3)}$ observaram que, de 17 garanhões utilizados para a criopreservação de sêmen, as variáveis pós-descongelamento foram superiores quando se utilizou metilformamida e dimetilformamida em 15 deles.

Segundo Gomes et al. ${ }^{(3)}$, o uso das amidas em garanhões de boa congelabilidade não proporciona melhora da motilidade e os resultados são semelhantes àqueles obtidos com o glicerol. Entretanto, em garanhões que apresentam baixa tolerância à criopreservação, como a maioria das raças nacionais, as amidas são mais eficazes em conferir proteção à célula espermática ${ }^{(3,8,11,12)}$.

Os resultados deste experimento reafirmaram os relatos da literatura quanto à combinação das amidas com o glicerol ser mais eficaz que a utilização isolada do glicerol como crioprotetor, em especial numa raça considerada como de baixa resistência ao processo de criopreservação, como o Mangalarga Marchador. 


\section{Conclusão}

Para o sêmen de garanhões da raça Mangalarga Marchador, considerados de baixa congelabilidade, diluentes que combinam concentrações de glicerol de 1 ou $2 \%$, com crioprotetores alternativos como a metilformamida e dimetilformamida, foram mais eficazes na proteção da célula espermática pós-descongelamento, quando comparados ao diluente contendo apenas o glicerol na concentração de $5 \%$.

\section{Referências}

1. Fagundes B, Van Tilburg MF, Souza GV, Caiado JRC, Barreto MAP, Silva JFS. Effect of addition of concentrated proteins and seminal plasma low molecular weight proteins in freezing and thawing of equine semen. Acta Biomedica Brasiliensia. 2011;2(1):1-7.

2. Miller CD. Optimizing the use of frozen-thawed equine semen. Theriogenology. 2008;70(3):463-468. Disponível em: 〈http://dx.doi.org/10.1016/j.theriogenology.2008.04.037> . Acesso em fevereiro de 2015.

3. Gomes GM, Jacob JCF, Medeiros ASL, Papa FO, Alvarenga MA. Improvement of stallion spermatozoa preservation with alternative cryoprotectants for the Mangalarga Marchador breed. Theriogenology. 2002;58(2-4):277-279. Disponível em: 〈http://dx.doi.org/10.1016/S0093-691X(02)00899-3>. Acesso em fevereiro de 2015.

4. CBRA (COLÉGIO BRASILEIRO DE REPRODUÇÃO ANIMAL). Manual para exame andrológico e avaliação de sêmen animal: manual de orientação. 3. ed. Belo Horizonte, MG:CBRA, 2013. 104p. Portuguese.

5. Harrison RAP, Vickers SE. Use of fluorescent probes to assess membrane integrity in mammalian spermatozoa. J Reprod Fertil. 1990;88(1):343-352.

6. Klinc P, Rath D. Reduction of oxidative stress in bovine spermatozoa during flow cytometric sorting. Reprod Domest Anim. 2007;42(1):63-67.

7. Hoffmann H, Oldenhof H, Morandini C, Rohn K, Sieme H. Optimal concentrations of cryoprotective agents for semen from stallions that are classified 'good' or 'poor' for freezing. Anim Reprod Sci. 2011;125(1-4):112-118. Disponível em: 〈http://dx.doi.org/ 10.1016/j.anireprosci.2011.03.001〉. Acesso em fevereiro de 2015.

8. Medeiros ASL, Gomes GM, Carmo MT, Papa FO, Alvarenga MA. Cryopreservation of stallion sperm using different amides. Theriogenology. 2002;58(2-4):273-276. Disponível em: <http://dx.doi.org/10.1016/S0093-691X(02)00898-1>. Acesso em fevereiro de 2015.

9. Alvarenga MA, Leão KM, Papa FO, Landim-Alvarenga FC, Medeiros ASL, Gomes GM. The use of alternative cryoprotectors for freezing stallion semen. In: WORKSHOP ON TRANSPORTING GAMETES AND EMBRYOS, 12., 2003, Brewster, Massachusetts. Anais... New York: Havemeyer Foundation Monograph $2003 . \quad$ Series, $274-76 . \quad$ Disponível em: $<$ http://www.havemeyerfoundation.org/PDFfiles/Brewster\%20Monograph.pdf\#page=86 $>$. Acesso em abril 2015.

10. Terraciano PB, Bustamante Filho IC, Miquelito LV, Arlas TR, Castro F, Mattos RC, Passos EP, Oberst ER, Lima EOC. Criopreservação de espermatozoides equinos comparando duas curvas de congelamento combinadas com diluentes comerciais: uma análise laboratorial. Cienc. Rural. 2008;38(7):1972-1977. 
11. Candeias ML, Alvarenga MA, Carmo MT, Ferreira HN, Souto Maior MR, Torres Filho RA, Rodrigues ALR, Brandão FZ. Semen cryopreservation protocols of Mangalarga Marchador stallions. R. Bras. Zootec. 2012;41(9):1989-1995. Disponível em: 〈http://dx.doi.org/10.1590/S1516-35982012000900004〉. Acesso em fevereiro de 2015.

12. Oliveira RA, Rubin MIB, Silva CAM. Índice de prenhez com sêmen congelado de garanhões da raça crioula usando glicerol ou dimetilformamida como crioprotetores. Cienc. anim. bras. 2013;14(4):488-494. Disponívem em: 〈http://dx.doi.org/10.5216/cab.v14i4.18923〉. Acesso em fevereiro de 2015.

13. Bedford SJ, Jasko DJ, Graham JK, Amann RP, Squires EL, Pickett BW. Effect of seminal extenders containing egg yolk and glycerol on motion characteristics and fertility of stallion spermatozoa. Theriogenology. 1995;43(5):955-967.

14. Ball BA, Vo A. Osmotic tolerance of equine spermatozoa and the effects of soluble cryoprotectants on equine sperm motility, viability and mitochondrial membrane potential. J Androl. 2001;22(6):1061-1069.

15. Alvarenga MA, Papa FO, Landim-Alvarenga FC, Medeiros ASL. Amides as cryoprotectants for freezing stallion semen: A review. Anim Reprod Sci. 2005;89(1-4):105-113.

16. Pace MM, Sullivan JJ. Effect of insemination, number of spermatozoa and extender components on the pregnancy rate in mares inseminated with frozen stallion semen. J Reprod Fertil Suppl. 1975Oct;(23):115121.

17. Medeiros ASL. Resistência osmótica, congelabilidade e fertilidade do sêmen de garanhões frente a diferentes crioprotetores. 2007, Botucatu, 123f. Tese (Doutorado em Medicina Veterinária) - Faculdade de Medicina Veterinária e Zootecnia - Unesp, Botucatu. Disponível em <http://www.dominiopublico.gov.br/pesquisa/DetalheObraForm.do?select action=\&co obra=87262>. Acesso em fevereiro de 2015.

18. Ferreira HN. Efeito da exposição aos crioprotetores glicerol e metilformamida na viabilidade e fertilidade do sêmen equino. 2008, Botucatu, 81f. Dissertação (Mestrado em Medicina Veterinária) - Faculdade de Medicina Veterinária e Zootecnia, Unesp, Botucatu. Disponível em <http://www.acervodigital.unesp.br/handle/123456789/31964>. Acesso em fevereiro de 2015. 